\title{
Psychometric properties of a Brazilian Portuguese version of the Children's Revised Impact of Event Scale (CRIES-8)
}

\author{
Sabrina de Sousa Magalhães1, Diana Kraiser Miranda1, Jonas Jardim de Paula ${ }^{1,2}$, Débora Marques de Miranda ${ }^{1,3}$, \\ Marco Aurélio Romano-Silva1,4, Leandro Fernandes Malloy-Diniz',4
}

1 Laboratory of Molecular Medicine, Federal University of Minas Gerais (UFMG), Belo Horizonte, MG, Brazil.
2 Department of Psychology, Faculty of Medical Sciences of Minas Gerais, Belo Horizonte, MG, Brazil.
${ }^{3}$ Department of Pediatrics, Federal University of Minas Gerais (UFMG), Belo Horizonte, MG, Brazil.
${ }^{4}$ Department of Mental Health, Federal University of Minas Gerais (UFMG), Belo Horizonte, MG, Brazil.

Institution where the study was conducted: Faculty of Medicine, Federal University of Minas Gerais (UFMG). Av. Prof. Alfredo Balena, 190, sala 114, Centro - 30130-100 Belo Horizonte, MG, Brazil.

Received: 08/18/17 - Accepted: 04/13/18

DOI: 10.1590/0101-60830000000151

Magalhães SS et al. / Arch Clin Psychiatry. 2018;45(2):27-32

\begin{abstract}
Background: Children and adolescents are considered a population at risk for developing posttraumatic stress disorder (PTSD) after a traumatic event. The Children's Revised Impact Scale (CRIES-8) is a self-report scale with 8 items that investigates avoidance and intrusion behaviors related to posttraumatic stress symptoms. Objective: The study consisted of translation and transcultural adaptation of CRIES-8 to Brazilian Portuguese and evaluation of its psychometric properties. Methods: A sample of 235 Brazilian children and adolescents exposed to natural hazards (drought or flood) and non-exposed children participated in the study. The methodological procedure for translation and cultural adaptation were in accordance with the principles described by ISPOR Task Force for Translation and Cultural Adaptation. We also evaluated test reliability and validity based on test content, the relations to other variables, and internal structure. Results: The procedures lead to a final Portuguese version proofread and cultural-adapted. Empirical evidence supports CRIES-8's division in two latent constructs (Intrusion and Avoidance), as well convergence correlations with other measures of child mental health and high reliability. Discussion: A Brazilian-Portuguese version of CRIES-8 is an important tool for a better screening of PTSD among youth who face traumatic events, being a potential informative instrument to identify children at risk.
\end{abstract}

Keywords: Post-traumatic stress disorders, child, psychological trauma, natural disasters, CRIES-8.

\section{Introduction}

From natural to human-made/technological events, disasters are potentially traumatic events. Virtually all people affected by a traumatic event exhibit posttraumatic stress (PTS) symptoms in some level, even though the full diagnostic criteria for posttraumatic stress disorder (PTSD) may not be fully reached ${ }^{1}$. The acute traumatic stress is the more common response after a disaster and it is associated with symptoms that show a tendency to disappear after safety conditions are restored ${ }^{2-5}$

Children and adolescents are usually more affected than adults after a traumatic event. Along with other vulnerable population, they are at a higher risk of developing PTSD after a stressful event, especially the youngest ones ${ }^{6}$. Circumstances of life-threatening, a probability of being apart from family, less efficient coping strategies, and disturbances in social support all account for the anxiety-like response after disasters ${ }^{6,7}$.

PTSD can be defined as an anxiety disorder triggered by severe traumatic life stress. It was not until 1987 that childhood PTSD has been recognized as different from adult trauma. Rather than responding to a traumatic situation with helplessness or fear, children may exhibit an agitated or disorganized behavior, as well as physical symptoms, such as headaches. Therefore, when assessing children's PTSD it is crucial to be prepared to deal with their peculiarities related to the developmental levels.

For children older than 6 years, the DSM- 5 diagnostic criteria for PTSD are: the need of exposure to an actual or threatened death, serious injury, or sexual violence through directly experiencing the traumatic event, witnessing it, having awareness that it happened to a family member or friend or by re-experiencing the traumatic event.
PTSD symptoms can be divided into four main clusters. The first one comprises reliving the traumatic event through intrusive memories and nightmares or physiological and psychological suffering when the trauma is recollected. The second cluster is related to persistent avoidance behavior and include the following symptoms: attempts to avoid feelings and thoughts associated with the event, and to avoid external reminders (people or activities) that are related to re-experiencing the trauma. The third cluster consists of negative alteration in cognitions and mood following the traumatic event. The last cluster is related to arousal symptoms and is marked by irritability, aggressive behavior, hypervigilance, sleep disturbances and difficulty to concentrate. The symptoms should persist for at least one month after the traumatic event and result in impairment to one's functioning 8,9 .

Screening tools are regarded as important instruments to evaluate effects following a distress, being considered reliable and cost-effective. Horowitz et al. ${ }^{10}$ first developed the Impact of Event Scale (IES) to assess the effect of traumatic events experienced. This original version counted with 15 items, and two clusters of symptoms Intrusion and Avoidance, but it is applied solely in adults. The next step was to produce a shortened version of the scale to be used among children and adolescents. For this purpose, seven items were excluded, and the remaining eight were adapted to a younger population ${ }^{11}$. The new version, Children's Revised Impact of Event Scale (CRIES-8), consists of 4 items measuring Intrusion and 4 items measuring Avoidance, becoming one of the most widely used screening tools for evaluating PTSD among children and adolescents ${ }^{5}$. Studies investigating the reliability and consistency of the scale have shown that PTSD is not culture bound and its factor structure has been proven to be stable across gender, age and different types of trauma ${ }^{12-14}$. 
The main aim of this study is to describe the process of translation and cultural adaptation of CRIES- 8 to a Portuguese version. Secondly, we aim to investigate the psychometric properties of the Brazilian version of CRIES-8, which includes validity and reliability, in a sample of children affected by flood or drought. Among the numerous events that could result in trauma, we selected a sample from those exposed to natural disaster. At present, the world is facing a substantial growth of these extreme events due to environmental changes related to global warming ${ }^{15}$. In Brazil, flood and drought are the most common natural adversities and the main cause of human damage and a similar pattern is also observed worldwide ${ }^{16,17}$.

\section{Methods}

\section{Participants}

Different samples were used according to the specific methods of the study. For the psychometric properties analysis, the sample consists of Brazilian children exposed to an adverse climate condition, especially drought or flood $(n=146)$, and a control group not exposed to the specific climate stressor considered. Children from the drought subgroup lived at Rio Pardo de Minas or Francisco Sá, both cities at the semi-arid zone of Minas Gerais state, Brazil. For the flood subgroup, children from Rio Branco, state of Acre, were recruited. This city is located in the north of Brazil and in 2015 it faced the worst flood incident of its history. The survey in Rio Branco was conducted up to 40 days after the peak of the disaster. The mean age for the exposed group was $11.17( \pm 3.30)$ and 77 were female. For the non-exposed group, students from two public schools at Belo Horizonte, capital state of Minas Gerais, were recruited $(n=89)$. The mean age was $11.06( \pm 2,74)$ and 56 were female.

\section{Assessment}

\section{CRIES}

CRIES- 8 is a screening tool for PTS symptoms in children, aged 8 and above and which reading abilities are sufficiently developed to understand and interpret the items. The scale is self-administrated and consists of 8 items, 4 measuring Intrusion (items 1, 3, 6, and 7) and 4 measuring Avoidance (items 2, 4, 5, 8). The items are scored on a four-point scale: "not at all" receives 0 scores, "rarely" sums 1 point, "sometimes" adds 3 points, and "often" computes 5 points. The Intrusion and Avoidance subscales are obtained counting the respective point for the appropriate subscale item. CRIES has more than 25 translations in different languages. All of it is available free of charge on the website of Children and War Foundation (http://www.childrenandwar.org).

\section{CBCL}

The Child Behavior Checklist (CBCL) consists of a questionnaire, answered by a caregiver, to identify behavior problem in schoolaged children from 6 to 18 years old ${ }^{18}$. In this study, we used the Internalizing Problems category, which is composed by the sum of the anxious/depressed, withdrawn-depressed, somatic complaints, social problems, thought problems, and attention problems raw scores; the Externalizing Problems category that resides on rule-breaking behavior and aggressive behavior raw scores; and the Total Problems raw score. Higher scores indicate greater problems.

\section{Study design}

The translation and cultural adaptation of CRIES- 8 are part of a broader project to study the impact of extreme natural events on children mental health conducted by our research group, which was approved by the local Ethics Committee. The procedure of transcultural adaptation was conducted following the practices described by Wild et al. ${ }^{19}$ which comprises ten steps described in Figure 1.

\section{Step 1. Preparation}

Contact the instrument manager to obtaim the permission of use and translation of the instrument and to invite him/her to be involved in the process. The Children anda war foundation authorized the work.

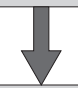

Step 2. Translation and Cultural Adaptation Process

Two independent direct translations (by two individuals whose language was Brazilian Portuguese and who were both fluent in English) verify possible divergent comprehension of items in the original and reduce potential bias interpretation and selection of items.

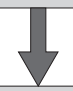

Step 3. Reconciliation

The two translations was compared and when any differences were identified, the item was discussed aiming a consensus between the two versions. Alternative translations were necessary to achieve final agreement and. afterward. the translations were merged into a single forward one.

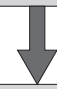

Step 4. Back translation

The Brazilian Portuguese version was-translated to english by a professional translator who did not have access to the initial version and had no prior knowledge of the measure.

Step 5. Back translation review
One management of the instrument reviewed the back-translated version
of the instrument in order to verify whether there were any semantic
differences or ambiguities between the original and the translated
Brazilian Portuguese versions.

Step 6. Harmonization

Afther the remarks from the management, the discrepancies were amendedin in the present stage.

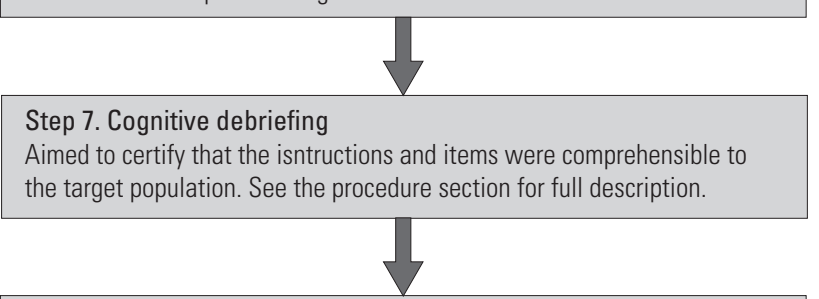

Step 8. Review of cognitive debriefing and finalization Comprise an analysis of the data gathered with the previous practice and an incorporation of any suggestion or modification whether required.

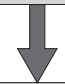

Step 9. Proofreading

Revision of the final translation by a Portuguese speaker to chevk for typographic, grammatical or other errors.

Step 10. Final report

Write a report with full description of the procedures and translation process

Figure 1. Flow chart with methodological steps to Translation and Cultural Adaptation process, according to ISPOR Translation and Cultural Adaptation Task Force ${ }^{19}$ 
The seventh step for Translation and Cultural Adaptation process, namely the Cognitive Debriefing, was performed by five young boys from Rio Pardo de Minas, and by four young children from Sabará, a city at the center of Minas Gerais state that faced flood consequences. Their age ranged from 6 to 13 years old (mean age 8,67 $\pm 2,45$ years) and they were all primary students of public schools. A five-point verbal numerical scale ${ }^{20}$ was used to assess the comprehensibility of the CRIES. The guide question was: "Do you understand what has been asked?". The participant should choose between the minimum value 0 ("I don't understand anything") to the maximum value 5 ("I understand perfectly, and I do not have any doubts about it"). The correspondent meaning of the extreme values was displaced above the numbers. The question must reach at least three points to be considered with satisfactory comprehension. For all the items, the participants had the option to suggest any modifications to improve understanding.

After transcultural adaption procedures, we investigated CRIES-8 psychometric properties. We evaluated the reliability by computing internal consistency using Cronbach's alpha and Split-Half methods. Validity was investigates focusing on test content (assessment by different judges during transcultural adaptation), its association with other variables (correlations with CBCL scores and comparison of youths exposed and non-exposed to natural disasters) and by assessment of internal structure (exploratory and confirmatory factor analysis). The latter procedure involved a principal component analysis with oblique rotation and confirmatory factor analysis using a diagonally weighted least squares method, commonly adopted to analyze ordinal data. Fit indexes commonly adopted in psychometric studies were computed, including Comparative Fit Index (CFI); Tucker-Lewis Index (TLI); Root Mean Square Error of Approximation (RMSEA).

\section{Results}

The process of transcultural adaptation of CRIES- 8 began with an initial translation which was back-translated to the original language, English (see Table 1), then members of the Children and War Foundation reviewed it. Any discrepancies, semantic differences or conceptual nonequivalence were investigated and highlighted. Five items received a critical observation (question 2, 3, 4, 6, and 7) because they did not adequately correspond to the concept depicted in the original version. Subtle lexical and grammar differences were identified between the meaning of original terms in English and the supposed equivalent words chosen in Portuguese. For question 2, was identified a different meaning between remove and think in erasing, one being more permanent than the other. Due to the failed first attempt to proper translate the expression waves of strong feelings depicted in question 3 , the reviewers emphasized the importance of stressing that the moment when an emotion affects someone is in a suddenly and profoundly manner. Lastly, the question 7 received a syntactic critic because of its construction. If the auxiliary do was used, the intention was to only ask whether the action occurs; on the other hand, the verb to be implied an interest in what other things trigger memories of the traumatic event. Another harmonization process was conducted to overcome these discrepancies and to ensure the equivalence between the versions.

Only one item remained the same, despite the back-translation review. The original item, question 6, "Do pictures about it pop into your mind?" was back-translated to "Do images from the event suddenly pop up in your head?". The replacement of mind to head was a matter of cultural adaptation. In Brazil, we often assign to head instead of mind to refer to daily cognitive activity.

For cognitive debriefing process, nine children classified the instructions and all the eight items of CRIES, accordingly to their understanding. They did not present any suggestions to improve the comprehension of the items. Only for the first question, a participant claimed not to understand it at all, probably due to his initial difficulty to understand what had been proposed with the task, as his original tendency was to answer the CRIES questions themselves. The question 2 also received a critical minimum rate. Further investigations at the moment of the evaluation revealed that some children recognize two different meaning for a keyword of the question. In Portuguese, the word lembrança is equivalent to memory, as well it can mean a gift someone gives to another. Nonetheless, because the meaning of retaining and recalling something was also recognized we decided to keep the word. Thus, the scale obtained suitable rates and therefore gathered its first evidence of validity.

The final proofreading checked for grammatical errors, the plausibility of comprehension by children population due to the concrete thinking they exhibit, and for theoretical consistency, to ensure the validity of test content. Table 1 presents the original CRIES version, the back-translated Portuguese version and the final Portuguese version.

For investigation of other psychometric properties of CRIES and the internal structure of the Portuguese CRIES- 8 version, we

Table 1. Versions of CRIES accordingly to the translations and adaptation process

\begin{tabular}{|c|c|c|}
\hline Original CRIES version & $\begin{array}{l}\text { Back-translated Brazilian } \\
\text { Portuguese version }\end{array}$ & \begin{tabular}{|l} 
Final Brazilian \\
Portuguese version
\end{tabular} \\
\hline $\begin{array}{l}\text { Below is a list of } \\
\text { comments made by } \\
\text { people after stressful } \\
\text { life events. Please tick } \\
\text { each item showing } \\
\text { how frequently these } \\
\text { comments were true for } \\
\text { you during the past seven } \\
\text { days. If they did not occur } \\
\text { during that time please } \\
\text { tick the "not at all" box. }\end{array}$ & $\begin{array}{l}\text { Below there is a list } \\
\text { of comments made by } \\
\text { people after stressful } \\
\text { events. Please, mark the } \\
\text { item that corresponds } \\
\text { to the frequency these } \\
\text { comments were true for } \\
\text { you during the last seven } \\
\text { days. If they did not } \\
\text { happen during this time } \\
\text { choose the option "not } \\
\text { at all". }\end{array}$ & $\begin{array}{l}\text { Abaixo se encontra } \\
\text { uma lista de } \\
\text { comentários feitos por } \\
\text { pessoas após eventos } \\
\text { estressantes. Por } \\
\text { favor, marque o item } \\
\text { que apresenta com } \\
\text { qual frequência esses } \\
\text { comentários foram } \\
\text { verdadeiros para você } \\
\text { durante os últimos } \\
\text { sete dias. Se eles não } \\
\text { aconteceram durante } \\
\text { esse período, marque } \\
\text { a opção “Nenhum } \\
\text { pouco". }\end{array}$ \\
\hline $\begin{array}{l}\text { 1. Do you think about } \\
\text { it even when you don't } \\
\text { mean to? }\end{array}$ & $\begin{array}{l}\text { 1. Do you think about it } \\
\text { even when you do not } \\
\text { want to? }\end{array}$ & $\begin{array}{l}\text { 1. Você pensa nisso } \\
\text { mesmo quando não } \\
\text { quer? }\end{array}$ \\
\hline $\begin{array}{l}\text { 2. Do you try to remove it } \\
\text { from your memory? }\end{array}$ & $\begin{array}{l}\text { 2. Do you think in erasing } \\
\text { it out of your memory? }\end{array}$ & $\begin{array}{l}\text { 2. Você tenta afastar } \\
\text { isso da sua lembrança? }\end{array}$ \\
\hline $\begin{array}{l}\text { 3. Do you have waves of } \\
\text { strong feelings about it? }\end{array}$ & $\begin{array}{l}\text { 3. Do you have moments } \\
\text { with strong feelings about } \\
\text { what has happened? }\end{array}$ & $\begin{array}{l}\text { 3. Você tem momentos } \\
\text { em que sentimentos } \\
\text { fortes sobre o que } \\
\text { aconteceu invadem } \\
\text { seus pensamentos? }\end{array}$ \\
\hline $\begin{array}{l}\text { 4. Do you stay away } \\
\text { from reminders of it (e.g. } \\
\text { places or situations)? }\end{array}$ & $\begin{array}{l}\text { 4. Do you stay away from } \\
\text { stuff, places or situations } \\
\text { that make you remember } \\
\text { what has happened? }\end{array}$ & $\begin{array}{l}\text { 4. Você fica longe de } \\
\text { lugares ou situações } \\
\text { que Ihe fazem lembrar } \\
\text { o que aconteceu? }\end{array}$ \\
\hline $\begin{array}{l}\text { 5. Do you try not talk } \\
\text { about it? }\end{array}$ & $\begin{array}{l}\text { 5. Do you try not to talk } \\
\text { about it? }\end{array}$ & $\begin{array}{l}\text { 5. Você tenta não falar } \\
\text { sobre isso? }\end{array}$ \\
\hline $\begin{array}{l}\text { 6. Do pictures about it pop } \\
\text { into your mind? }\end{array}$ & $\begin{array}{l}\text { 6. Do images from the } \\
\text { event suddenly pop up in } \\
\text { your head? }\end{array}$ & $\begin{array}{l}\text { 6. Imagens do } \\
\text { acontecimento surgem } \\
\text { de repente na sua } \\
\text { cabeça? }\end{array}$ \\
\hline $\begin{array}{l}\text { 7. Do other things keep } \\
\text { making you think about it? }\end{array}$ & $\begin{array}{l}\text { 7. Are there other things } \\
\text { that make you keep on } \\
\text { thinking about what has } \\
\text { happened? }\end{array}$ & $\begin{array}{l}\text { 7. Outras coisas fazem } \\
\text { você ficar pensando } \\
\text { sobre o que aconteceu? }\end{array}$ \\
\hline $\begin{array}{l}\text { 8. Do you try not to think } \\
\text { about it? }\end{array}$ & $\begin{array}{l}\text { 8. Do you try not to think } \\
\text { about it? }\end{array}$ & $\begin{array}{l}\text { 8. Você tenta não } \\
\text { pensar sobre isso? }\end{array}$ \\
\hline Not at all & Not at all & Nenhum pouco \\
\hline Rarely & Rarely & Raramente \\
\hline Sometimes & Sometimes & De vez em quando \\
\hline Often & A lot & Muitas vezes \\
\hline
\end{tabular}


evaluated a sample of 146 children affected by flood or drought and 89 children for control group. All indices of CRIES significant correlated with each other (data not show). Reliability analysis accessed through Cronbach's alpha and Split Half methods achieved an index of 0.79 and 0.83 , respectively, for total sample $(N=235)$. The scales achieve a Cronbach's alpha at 0.79 for Intrusion and 0.77 for Avoidance subscales, for total sample. Table 2 exhibits reliability analysis for the subgroups according to different methods.

A principal component analysis, with promax rotation, exhibited a solution with 2 factors and it explained $55.37 \%$ of the variance (Table 3). The Bartlett's Test of Sphericity was significant $(p<0.001)$ and the KMO was 0.82 , which indicate the adequacy of the sample. A confirmatory factor analysis tested the original two-factor solution (Intrusion and Avoidance). The final model sustained the original two-factor solution, with adequate fit-indexes $\left(\chi^{2}=39.98, \mathrm{df}=10\right.$, $\chi^{2} / \mathrm{df}=2.05, \mathrm{CFI}=0.98, \mathrm{TLI}=0.98$, $\left.\mathrm{RMSEA}=0.067\right)$.

Another question addressed was whether CRIES-8 could be related to a screening tool for children behavioral problems (validity based on association with other measures). We recruited another sample of 91 healthy children, non-exposed to any specific stressful event, as a comparison group. There were no significant differences between the groups concerning age, years of formal schooling and $\operatorname{sex}(p=0.85, p=0.79$, and $p=0.18$, respectively). All CRIES scores indicated that those who experienced an adverse condition reported more symptoms of intrusion and avoidance related to the event, compared to those non-exposed to stressful condition. However, if we considered the cut-off score of 17 reported by Perrin et al. ${ }^{21}$ to positive screening for PTSD, both groups did not reach this threshold. The Cohen's $d$ effects sizes were moderate. There were no significant differences between groups in any kind of behavior problems described by the parent and both groups did not show any significant clinical problem in average accessed by the CBCL (Table 4).

To further evaluate its validity by its association with other measures we correlated CRIES total score with CBCL. We found significant correlations with CBCL internalizing problems $(r=0,16$, $p=0,05)$ and CBCL total problems score $(r=0,16, p=0,05)$. The avoidance index of CRIES is associated with the CBCL total problems $(r=0,18, p=0,05)$ and the intrusion index is not correlated with any CBCL measures.

\section{Discussion}

Our study resulted in a transcultural adaptation of CRIES- 8 for Brazilian-Portuguese. This version succeeds in reaching meticulous methodological steps to establish language adequacy, cultural adjustment, and language standards. Besides the translation procedures, we found evidences of validity and reliability for the adapted version, including moderate to high internal consistency, a two-components latent structure, significant score differences by children exposed and non-exposed to natural disasters and weak but significant correlations with other measures of behavioral problems.

After a trauma, most children do not develop PTSD 22. Nevertheless, subclinical levels of PTS symptoms can significant impair social and educational functioning, and could impact psychological and developmental process. Age and the stage of development can lead to a greater recognition and memories of the event, jeopardizing mental health ${ }^{21}$. CRIES- 8 is highly regarded as an important tool for screening children at risk for PTSD. The instrument is widely used in a variety of cultures, since posttraumatic stress symptoms in children have more similarities than differences from one place to the other ${ }^{21}$. As these versions enhance the worldwide comparability of research of the effects of disasters on children, it will be important and useful to introduce CRIES-8 in Brazil. In fact, it promptly covers a lack of valid and adapted instruments for these purposes in Brazil. To our knowledge, this is the first free PTSD screening tool adapted for Brazilian children and adolescents.

Reliability indices were moderate; however, the two distinct methods provide convergent results. Moderate values are expected in

Table 2. Reliability analysis for children exposed and non-exposed to an adverse condition related to natural hazard, according to different methods ( $N=235$ )

\begin{tabular}{|c|c|c|c|c|c|c|}
\hline & \multicolumn{3}{|c|}{ Exposed $(n=146)$} & \multicolumn{3}{c|}{ Non-exposed $(n=89)$} \\
\hline & CRIES & Intrusion subscale & Avoidance subscale & CRIES & Intrusion subscale & Avoidance subscale \\
\hline Cronbach's alpha & 0.80 & 0.73 & 0.73 & 0.89 & 0.86 & 0.80 \\
\hline Split Half & 0.84 & 0.77 & 0.70 & 0.89 & 0.85 & 0.81 \\
\hline
\end{tabular}

Table 3. Principal components analysis of Portuguese CRIES-8 version, with promax rotation

\begin{tabular}{|l|c|c|}
\hline \multirow{2}{*}{} & \multicolumn{2}{|c|}{ Loading } \\
\hline & Factor 1 Intrusion & Factor 2 Avoidance \\
\hline 6. Do pictures about it pop into your mind? & $\mathbf{0 . 7 6}$ & \\
\hline 7. Do other things keep making you think about it? & $\mathbf{0 . 7 3}$ & \\
\hline 1. Do you think about it even when you don't mean to? & $\mathbf{0 . 7 3}$ & 0.40 \\
\hline 3. Do you have waves of strong feelings about it? & $\mathbf{0 . 7 0}$ & 0.50 \\
\hline 4. Do you stay away from reminders of it (e.g. places or situations)? & $\mathbf{0 . 5 2}$ & $\mathbf{0 . 8 4}$ \\
\hline 8. Do you try not to think about it? & 0.41 & $\mathbf{0 . 8 3}$ \\
\hline 5. Do you try not talk about it? & & $\mathbf{0 . 7 2}$ \\
\hline 2. Do you try to remove it from your memory? & & \\
\hline
\end{tabular}

Table 4. Comparison between CRIES and CBCL indices for children exposed to adverse weather event (drought or flood) and non-exposed children

\begin{tabular}{|l|c|c|c|c|c|c|}
\hline & \multicolumn{2}{|c|}{ Exposed 1} & \multicolumn{2}{c|}{ Non-exposed ${ }^{2}$} & \multicolumn{2}{c|}{ Statistics } \\
\hline & Mean & SD & Mean & SD & d \\
\hline CRIES total score & 15.90 & 10.25 & 9.26 & 10.65 & $22.74^{*}$ & $\mathbf{0 . 6 3}$ \\
\hline CRIES intrusion & 7.44 & 5.73 & 4.09 & 5.70 & $18.95^{*}$ & $\mathbf{0 . 5 9}$ \\
\hline CRIES avoidance & 8.49 & 6.06 & 5.17 & 5.86 & $17.09^{*}$ & $\mathbf{0 . 5 6}$ \\
\hline CBCL Total Problems & 37.19 & 20.17 & 33.06 & 20.17 & 1.75 & 0.20 \\
\hline CBCL Internalizing Problems & 12.55 & 7.76 & 11.58 & 8.02 & 0.63 & 0.12 \\
\hline CBCL Externalizing Problems & 9.09 & 6.82 & 8.30 & 6.08 & 0.61 & 0.12 \\
\hline
\end{tabular}

${ }^{1} n=146$ for CRIES scores, and $n=111$ for CBCL scores; $2 n=89$ for CRIES scores; $n=67$ for CBCL scores; $p<0.001$. 
screening tests or scales, since the low number of items may influence the internal reliability. In this sense, lower internal consistency values are usually accepted for those measures ${ }^{23}$. The values obtained were coherent with international literature. Studies with distinguished disaster events usually report a Cronbach's alpha varying between 0.70 to 0.86 for the total score of CRIES-82,11,13,24. For the intrusion items, the Cronbach's alpha was reported at 0.60 to $0.88^{2,11,13,14,24,25}$. Finally, for the avoidance subscale, Cronbach's alpha was 0.58 to

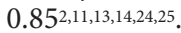

In exploratory principal component analysis, the underlying latent structure was similar to other versions of CRIES-8 $8^{13,14,21,25}$, with exception for the Question 4 that was supposed to count for Factor 2, Avoidance, although in our study it loads slightly more on Factor 1, Intrusion. Due to specificities of the trauma studied, children from both conditions (drought or flood) not always have the actual power to avoid places or situations that remind them of the disaster. The analysis of another sample exposed to a different traumatic event will help to elucidate this finding. However, a confirmatory factor analysis still corroborated the original items structure. Three of the four fit indexes showed optimal parameters $\left(\chi^{2} / \mathrm{gl}<3\right.$, CFI $>0.95$, TLI $>0.95)$ and one showed marginal results (RMSEA $<0.06)$. Our results corroborate the internal structure validity of CRIES-8.

We verified a significant difference in CRIES scores between the exposed and non-exposed group, with moderate effect sizes. Although no differences were found on CBCL between groups, CRIES- 8 better discriminated between groups of exposed and nonexposed. Thus, it was sensible to disclose distress symptoms that children probably were experiencing in consequence to the disaster.

PTSD is mainly an internal phenomena since it is characterized by a phenomenology of recollections, therefore not always clearly evident to others. This highlights the importance of self-report, especially child self-report data. We found a significant difference, with moderate size effects, between CRIES and CBCL scores. The apparent divergence between CRIES scores and the CBCL scores may be under the assumption that parents in a context of adversities may not be able in providing a suitable care for their kids, and their report could not be the most reliable concerning the experience of their children after an adverse experience. Furthermore, children and adolescents could exhibit a tendency to hide stress feelings and thoughts from their parents in order to preserve them from another source of distress. Therefore, the study suggests that child self-reports are the preferred source of information in the evaluation of youth PTSD.

In general, the significant correlations between CRIES and CBCL were few and modest. One hypothesis to explain the data may due to differences in self-reports and parental reports, as previously discussed. A second one could be due to the time period that the investigation occurs. Accordingly to DSM-5, PTSD symptoms usually appear within the first 3 months after the event ${ }^{9}$. For flood affected children, the acme of the rainy period occurred about one month previously to the data collection. On the other hand, CBCL requires parents to report the pattern of child behavior during the last 6 months. So the time lapse was before the peak of the disaster for the flood group and it could also include a different season with no rain/flood incidents.

This study has two important limitations. First, the original CRIES version was designed for children aged 8 or older, but we included children with 6 and 7 years of age $(n=31,13,2 \%$ of total sample). The original authors of CRIES argue that children young as 6 years old may not have the proper reading and comprehension skills to answer the scale and they do not recommend 6 years old children answering the scale. Regarding this, experimenters were instructed to help young children achieve a better comprehension of the items. The decision to maintain this young age group was due to our plan to follow-up this population for future symptoms.

The second limitation refers to the type of stressful event chosen to validate the scale. Children reactions to different types of disasters may be very specific to the event. Research with different traumatic contexts is highly desired to consolidate CRIES for a screening tool for PTSD in the Brazilian population. After all, some studies found a lower prevalence of PTSD after natural disasters than after humanmade/technological events ${ }^{26}$.

Areas in need of research include the factors that might modulate and mediate PTSD symptoms (e.g. disaster-related media exposure, prior trauma, social support), the assessment of the long-term impact of disasters, as well as how PTS symptoms relate to measures of daily functioning. Resilience should also be put in perspective, as it is often neglected by post-disaster studies. Future proceedings must include studies of validity evidence based on consequences of testing of CRIES- 8 for the diagnoses of PTSD and to verify a suitable cut off of CRIES- 8 for the Brazilian population.

Children and adolescents are a population deemed to be at risk following a disaster, especially because they are still in development and less prepared to deal with stress and drastic changes. Screening tools are especially useful in the context of experiencing stressful events, as they optimize the evaluation process, and objectively identifying potential impairments in one's life. The translation and cultural adaptation of CRIES- 8 to a Brazilian Portuguese version were conducted following gold standard guidelines to ensure the quality of the process ${ }^{19}$. The extensive revisions lead to a version that is intended to be comprehensible for even young children, it is theoretical representative of the two major factors of the scale (intrusion and avoidance), it is semantic equivalent to the original version, and empirical evidence supports his validity evidence based on test content, relations to other variables, internal structure, and the reliability of its measures. A further strength of the current study was the work definition of PTSD as a heterogeneous construct, which includes Intrusion and Avoidance symptoms.

\section{Acknowledgment}

This study was supported by Conselho Nacional de Desenvolvimento Científico e Tecnológico - CNPq (404047/2013-0), and Fundação de Amparo à Pesquisa do Estado de Minas Gerais - Fapemig (PPM00183-14).

The authors address special acknowledgment for the Children and War Foundation for the permission to adapt and translate CRIES-8 to Portuguese and also for collaborating in the review of the back-translated Portuguese version.

\section{References}

1. Hughes V. Stress: The roots of resilience. Nature. 2012;490(7419):165-7.

2. Chen Z, Zhang Y, Liu Z, Liu Y, Dyregrov A. Structure of the Children's Revised Impact of Event Scale (CRIES) with Children and Adolescents Exposed to Debris Flood. PLoS One. 2012;7(8):1-6.

3. Furr JM, Comer JS, Edmunds JM, Kendall PC. Disasters and youth: a meta-analytic examination of posttraumatic stress. J Consult Clin Psychol. 2010;78(6):765-80.

4. Green BL, Korol M, Grace MC, Vary MG, Leonard AC, Gleser GC, et al. Children and disaster: age, gender, and parental effects on PTSD symptoms. J Am Acad Child Adolesc Psychiatry. 1991;30(6):945-51.

5. Trickey D, Siddaway AP, Meiser-Stedman R, Serpell L, Field AP. A metaanalysis of risk factors for post-traumatic stress disorder in children and adolescents. Clin Psychol Rev. 2012;32(2):122-38.

6. Masten AS, Osofsky JD. Disasters and their impact on child development: introduction to the special section. Child Dev. 2010;81(4):1029-39.

7. McDermott BM, Cobham VE, Berry H, Stallman HM. Vulnerability factors for disaster-induced child post-traumatic stress disorder: the case for low family resilience and previous mental illness. Aust N Z J Psychiatry. 2010;44(4):384-9.

8. Salmon K, Bryant RA. Posttraumatic stress disorder in children. The influence of developmental factors. Clin Psychol Rev. 2002;22(2):163-88.

9. American Psychiatric Association. Diagnostic and statistical manual of mental disorders. 5th ed. Washington, D.C.: American Psychiatric Association; 2013

10. Horowitz M, Wilner N, Alvarez W. Impact of Event Scale: a measure of subjective stress. Psychosom Med. 1979;41(3):209-18. 
11. Verlinden E, van Meijel EP, Opmeer BC, Beer R, de Roos C, Bicanic IA, et al. Characteristics of the Children's Revised Impact of Event Scale in a clinically referred Dutch sample. J Trauma Stress. 2014;27(3):338-44.

12. Beck JG, Grant DM, Read JP, Clapp JD, Coffey SF, Miller LM, et al. The impact of event scale-revised: psychometric properties in a sample of motor vehicle accident survivors. J Anxiety Disord. 2008;22(2):187-98.

13. Deeba F, Rapee RM, Prvan T. Psychometric properties of the Children's Revised Impact of Events Scale (CRIES) with Bangladeshi children and adolescents. PeerJ. 2014;2:e536.

14. Giannopoulou I, Smith P, Ecker C, Strouthos M, Dikajakou A, Yule W. Factor structure of the Children's Revised Impact of Event Scale (CRIES) with children exposed to earthquake. Pers Indiv Differ. 2006;40(5):1027-37.

15. IPCC, 2014: Climate Change 2014: Synthesis Report. Contribution of Working Groups I, II and III to the Fifth Assessment Report of the Intergovernmental Panel on Climate Change [Core Writing Team, Pachauri RK and Meyer LA (eds.)]. IPCC, Geneva, Switzerland, 151 p.

16. Anuário Brasileiro de Desastres Naturais: 2013/Ministério da Integração Nacional. Secretaria Nacional de Proteção e Defesa Civil. Centro Nacional de Gerenciamento de Riscos e Desastres. Brasília: CENAD; 2014.

17. Guha-Sapir D, Hoyois PH, Below R. Annual Disaster Statistical Review 2015: The Numbers and Trends. Brussels: CRED; 2016.

18. Bordin IAS, Mari JJ, Caeiro MF. Validação da versão brasileira do "Child Behavior Checklist" (CBCL) (Inventário de Comportamentos da Infância e Adolescência): dados preliminares. Rev ABPAPAL. 1995;2(17):55-66.

19. Wild D, Grove A, Martin M, Eremenco S, McElroy S, Verjee-Lorenz A, et al.; ISPOR Task Force for Translation and Cultural Adaptation.
Principles of Good Practice for the Translation and Cultural Adaptation Process for Patient-Reported Outcomes (PRO) Measures: report of the ISPOR Task Force for Translation and Cultural Adaptation. Value Health. 2005;8(2):94-104.

20. Grassi-Oliveira R, Stein LM, Pezzi JC. Tradução e validação de conteúdo da versão em português do Childhood Trauma Questionnaire. Rev Saúde Pública. 2006;40(2):249-55.

21. Perrin S, Meiser-Stedman R, Smith P. The Children's Revised Impact of Event Scale (CRIES): Validity as a Screening Instrument for PTSD. Behav Cogn Psychother. 2005;33:487-98.

22. Alisic E, Jongmans MJ, van Wesel F, Kleber RJ. Building child trauma theory from longitudinal studies: a meta-analysis. Clin Psychol Rev. 2011;31(5):736-47.

23. Mitrushina M, Boone KB, Razani J, Delia LF. Handbook of normative data for neuropsychological assessment. New York: Oxford University Press; 2005.

24. Lau JT, Yeung NC, Yu XN, Zhang J, Mak WW, Lui WW, et al. Validation of the Chinese version of the Children's Revised Impact of Event Scale (CRIES) among Chinese adolescents in the aftermath of the Sichuan Earthquake in 2008. Compr Psychiatry. 2013;54(1):83-90.

25. Oh EA, Park EJ, Lee SH, Bae SM. Validation of the Korean version of the Children's Revised Impact of Event Scale. Clin Psychopharmacol Neurosci. 2014;12(2):149-56.

26. Galea S, Nandi A, Vlahov D. The epidemiology of post-traumatic stress disorder after disasters. Epidemiol Rev. 2005;27:78-91. 